\title{
LCA of Glass Versus PET Mineral Water Bottles: An Italian Case Study
}

\author{
Carmen Ferrara, Giovanni De Feo*(D) and Vincenza Picone
}

Citation: Ferrara, C.; De Feo, G.; Picone, V. LCA of Glass Versus PET Mineral Water Bottles: An Italian Case Study. Recycling 2021, 6, 50. https://doi.org/10.3390/ recycling 6030050

Academic Editor: Michele John

Received: 12 May 2021

Accepted: 12 July 2021

Published: 15 July 2021

Publisher's Note: MDPI stays neutral with regard to jurisdictional claims in published maps and institutional affiliations.

Copyright: (c) 2021 by the authors. Licensee MDPI, Basel, Switzerland. This article is an open access article distributed under the terms and conditions of the Creative Commons Attribution (CC BY) license (https:// creativecommons.org/licenses/by/ $4.0 /)$.
Department of Industrial Engineering (DIIN), University of Salerno, via Giovanni Paolo II, 132-84084 Fisciano, Italy; cferrara@unisa.it (C.F.); v.picone@studenti.unisa.it (V.P.)

* Correspondence: g.defeo@unisa.it; Tel.: +39-089-964-113

\begin{abstract}
Due to the serious problem of plastic pollution in aquatic environment, many people reject plastic packaging in favour of glass containers which are considered more sustainable. To avoid misjudgements, the sustainability assessment of packaging alternatives should be carried out with a life cycle thinking approach. In this regard, the study presents a comparative Life Cycle Assessment (LCA) of two alternative packaging systems for drinking water: reusable glass bottles and polyethylene (PET) bottles. The case study was performed considering the real data of an Italian mineral water company that bottles and distributes both natural and sparkling water. The environmental impacts of the two packaging systems were estimated with the ReCiPe $2016(\mathrm{H})$ evaluation method adopting both midpoint and endpoint approaches. The results showed that the PET bottle is the most sustainable alternative for natural water for many impact categories; while, in the case of sparkling water, the environmental impacts of the two packaging systems are similar and the most environmentally sound solution can vary depending on the impact category. The following are the most significant aspects of the analysis: (1) the number of reuses of a single glass bottle; (2) the distribution distance. Their variation can determine which packaging is the most sustainable. Therefore, a life cycle assessment approach is needed for each specific case.
\end{abstract}

Keywords: sustainability; reusable glass bottle; PET bottle; beverage packaging; bottled water

\section{Introduction}

The serious environmental problem of plastic marine pollution has caused a growing global concern [1]. In this regard, at the European level, the "Single-Use Plastics Directive" (Directive (EU) 2019/904) sets new targets to limit the adoption of single-use plastic packaging (i.e., cups for beverages, including their covers and lids, and food containers) as well as to banish completely specific single-use plastic products (i.e., cotton bud sticks, cutlery, plates, straws, beverage stirrers, sticks to be attached to and to support balloons, food containers made of expanded polystyrene, beverage containers made of expanded polystyrene including their caps and lids, and cups for beverages made of expanded polystyrene including their covers and lids).

In response to the "plastic issue", many people reject plastic packaging for beverages with a preference for other packaging materials, especially glass, which is usually considered the most sustainable alternative [2]. For instance, many people mistakenly think that plastic bottles for mineral water are also among the products banned by the directive and that any plastic object automatically ends up in the oceans.

Therefore, in order to avoid a problem shifting issue, the adoption of a holistic approach is needed for the evaluation of the environmental sustainability of systems, using a life cycle thinking perspective [3].

Currently, life cycle assessment (LCA) is the most used methodology for the sustainability assessment of alternative systems. LCA allows for the comparison of the potential environmental impacts occurring during all the life cycle phases (e.g., raw material extrac- 
tion, manufacturing, processing, packaging, transportation, use, end-of-life) of alternative systems [4].

In this perspective, Kouloumpis et al. (2020) [5] used the LCA methodology to evaluate the environmental effects of the potential substitution of polyethylene terephthalate (PET) bottles with glass bottles for beverage in Cornwall and showed that this would lead to a significant increase in the environmental impact in terms of climate change.

Similar results also emerged from other papers that compared the environmental performances of PET and glass bottles for the packaging of beverage through the use of LCA. PET was the most environmentally sound alternative [6,7] not only in terms of global warming but also considering other environmental indicators such as eutrophication, terrestrial acidification, cumulative energy demand, etc. [8,9].

Currently, it is difficult to find effective alternatives to plastic packaging [10]. Compared to other types of packaging for beverage, such as polylactic acid (PLA) or aluminium bottles, the PET bottle seems to be the packaging solution that generates fewer impacts [11]. Furthermore, its environmental performances can be improved using recycled PET in the bottle production process [12]. Nevertheless, looking only at the embodied energy parameter (defined as the sum of all the energies required to produce the packaging), aluminium is the packaging material with the lowest value per L of beverage [13].

An environmentally competitive alternative to the PET bottle could be the reusable packaging. Indeed, Coelho et al. (2020) [14] pointed out that these alternatives can have environmental end economic benefits rather than single-use packaging. In this regard, some studies applied the LCA methodology to compare the environmental performances of a PET or HDPE bottles system and a reusable glass bottles system for the bottling of different types of beverage as mineral water [15], milk [16,17], wine [18] and soft drinks $[19,20]$. However, the results of the studies differ depending on the case study, the geographic location and the specific assumptions. The best environmental packaging solutions identified in these papers vary on the basis of three main key factors: the number of reuses for the glass bottle, the weight of the two types of bottles and the recycling rate of glass and PET. Nevertheless, these aspects strictly depend on the specific case considered. Therefore, it is very important to carry out further LCA studies on the topic based on original and site-specific inventory data referred to real cases.

In this regard, our study proposes a LCA application to the environmental comparison of two packaging systems for drinking water: reusable glass bottle (PS1_GLASS) and PET bottle (PS2_PET), using original and site-specific inventory data about the three key factors pointed out, in order to identify the most environmentally sound alternative on the basis of the real case of an Italian mineral water company that uses this packaging to commercialize both natural mineral water $(\mathrm{N})$ and sparkling mineral water $(\mathrm{S})$.

\section{Materials and Methods}

The LCA study was carried out in compliance to the four LCA phases, as recommended by the ISO standard (ISO 14040, 2006; ISO 14044, 2006): (i) Goal and scope definition; (ii) Life cycle inventory; (iii) Life cycle impact assessment; (iv) Results interpretation [21,22]. The first three phases are reported in the following sub-sections after the description of the packaging systems considered, while the last phase is discussed in the next section (Results and Discussion).

\subsection{Description of the Packaging Systems for Mineral Water}

The mineral water company under study is in the Campania region of Southern Italy. It uses two packaging systems for water: PET bottles (82\%) and single use or reusable glass bottles $(16 \%)$ in function of the water distribution distance. The study focused on the packaging systems of reusable glass bottles (PS1_GLASS) and PET bottles (PS2_PET), both of $1 \mathrm{~L}$ size, considering separately natural water and sparkling water. 
Reusable glass bottle, aluminium cap, paper label and glue for label are the primary packaging components of the PS1_GLASS system. All the components are produced in specialized packaging companies and then transported to the bottling company.

In the bottling plant, the first step for the reusable glass bottles is the washing process with hot water and chemicals necessary to clean and sterilize the bottles as well as to remove the labels. The wastewater produced in this phase are sent to a wastewater treatment plant. After the washing phase, the bottles are checked to verify their suitability. The bottles that do not pass the control phase are collected for the recycling and replaced with new glass bottles. After this phase, the bottles are filled with natural or sparkling water and then capped and labelled. Subsequently, they are packaged in plastic boxes (secondary packaging) that can contain 12 bottles and they are finally palletized. At this stage, the bottles are ready for distribution. This phase can be divided into two steps: first distribution from bottling plant to the distribution centres; second distribution from distribution centres to the retailers.

The bottling company recovers the empty glass bottles (after use) from its customers starting a new cycle while the other components are disposed of. According to the bottling company, the average number of reuses for the glass bottle is 6 .

PET preform, high density polyethylene (HDPE) cap, polyethylene (PE) label and glue for label are the primary packaging components of the PS2_PET system.

In the bottling plant, the PET bottles are obtained with a blow moulding process starting from PET preforms. Subsequently, the PET bottles are filled with natural or sparkling water and then capped and labelled. For this system, the secondary packaging is composed of a bundle (a PE film) that contains 6 bottles and a cardboard handle that makes handling easier. The last step in the bottling plant is the palletization of the system. At this stage, the bottles are ready for distribution: it is the same described for the PS1_GLASS system. After the use, all the components of the PS2_PET system are sent to their end-of-life.

\subsection{Goal and Scope}

Using a life cycle perspective, the main aim of the study was to identify the packaging system for mineral water with the best environmental performances considering the real situation of an Italian mineral water company that bottles and distributes both natural and sparkling water.

In accordance with other LCA studies about the comparison of packaging alternatives for beverage, the functional unit (FU) of the study was defined as all the packaging components required to package a volume of liquid $[16,23]$. More in detail, the FU was the packaging (considering all the components of the system) needed for bottling and distributing $1 \mathrm{~L}$ of natural mineral water and $1 \mathrm{~L}$ of sparkling mineral water. For this purpose, only the bottles of $1 \mathrm{~L}$ size were considered. Considering the real case of the water company under study, the two types of water were considered separately because there are some differences about: (i) the weight of some packaging components of the PS2_PET system; (ii) the distribution range (see Section 2.3). Therefore, the reusable glass bottle packaging system (PS1_GLASS (N)) and the PET bottle packaging system for natural water (PS2_PET (N)) were compared in environmental terms separately from the two packaging systems for sparkling water (PS1_GLASS (S) and PS2_PET (S)).

The analysis was carried out using a "from cradle to grave" approach. Therefore, in the system boundaries of the study, all the life cycle phases of the packaging systems were considered (Figure 1), except the water extraction phase (that is a common step to the two packaging systems considered, thus it does not affect the comparison) and the use phase. 


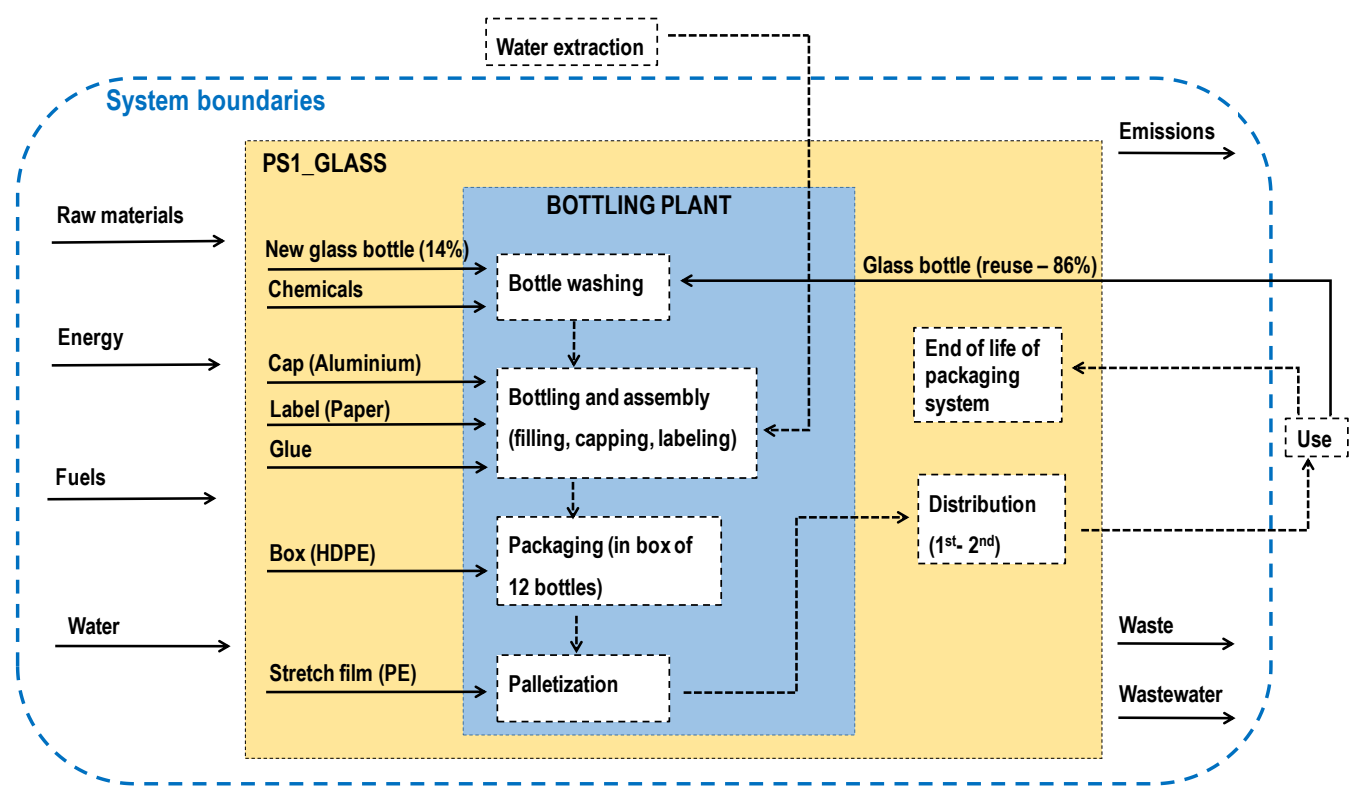

(a)

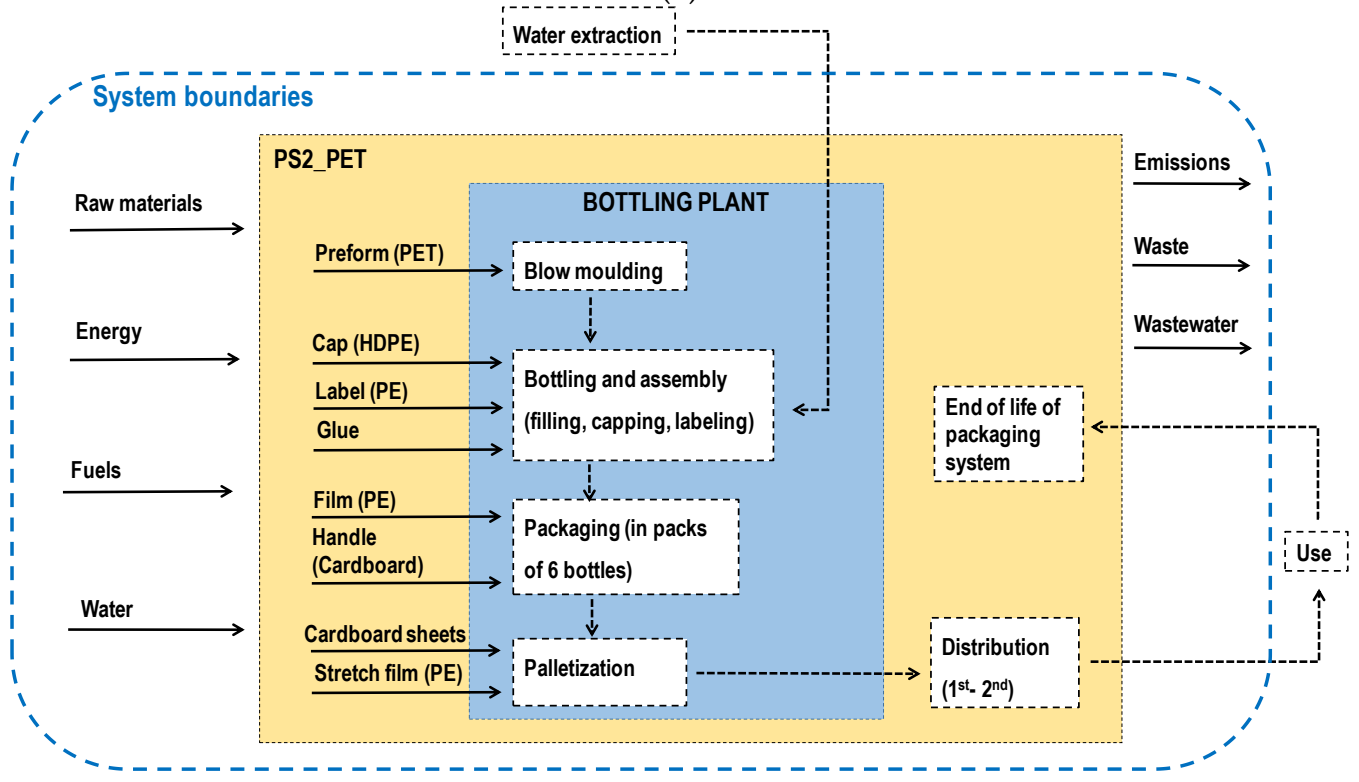

(b)

Figure 1. Scheme of system boundaries for the reusable glass bottle packaging system: PS1_GLASS (a) and for PET bottle packaging system: PS2_PET (N) and PS2_PET (b).

For both systems, the production of all the components of primary, secondary and tertiary packaging were considered with the following assumptions derived from the data and information provided by the bottling company:

- About the primary and secondary packaging of the systems, all the components (except the glass bottle) were produced with 100\% virgin raw materials;

- $\quad$ For the new glass bottles (i.e., those that replace the reusable bottles to be collected and sent to recycling) a recycled glass content of $70 \%$ in the production process of the bottles was considered because white glass is used and a lower recycled content is expected for this type of glass rather than for green glass bottles [4,23];

- $\quad$ Regarding to the tertiary packaging components, a recycled fibers content of $80 \%$ was considered in the production process of cardboard sheets while it was assumed that the PE stretch film was manufactured with only virgin PE. 
The distribution phase was modelled considering the real distribution range for natural water (about $213 \mathrm{~km}$ ) and for sparkling water (about $186 \mathrm{~km}$ ) commercialized in reusable glass bottles by the bottling company under study. Therefore, for PS2_PET (N) and for PS2_PET (S), the same distribution values considered for PS1_GLASS (N) and PS1_GLASS (S) were used, respectively. In addition to the first distribution just described, a second distribution was considered for all the packaging systems to also consider the transportation of the products from the distribution centres to the retailers: $30 \mathrm{~km}$ was assumed. The transport of the products from the retailers to the final customers was not considered.

Finally, the end-of-life of each component of the systems was considered. For this purpose, disposal scenarios composed of incineration, landfilling and recycling were modelled for all the packaging materials.

\subsection{Life Cycle Inventory}

The LCA models of all the packaging systems were performed using the SimaPro 8 software tool. Primary data regarding the production of the systems' components, the bottling plant operations and the distribution of natural and sparkling water were provided by the bottling company. Background data, as the Italian energy mix, the extraction and transportation of raw materials, fuels production, infrastructure and vehicles were taken from the processes of Ecoinvent v.3 database.

Tables 1 and 2 show the main inventory data regarding the weight and composition of all the components of the packaging systems considered. All the data are expressed in terms of the functional unit of the study.

Table 1. Weight and composition of all the components of the PS1_GLASS system (the values are the same for both natural and sparkling water).

\begin{tabular}{cc}
\hline PS1_GLASS & Weight (g) \\
\hline Glass bottle (1st Packaging) & 450 \\
Aluminium Cap (1st Packaging) & 2.0 \\
Paper label (1st Packaging) & 0.87 \\
Glue (1st Packaging) & 0.71 \\
HDPE box * (2nd Packaging) & 165.8 \\
PE stretch film (3rd Packaging) & 0.04 \\
Wood Pallet * (3rd Packaging) & 50 \\
\hline
\end{tabular}

* Component not considered in the production phase because of the high reuse number.

Table 2. Weight and composition of all components of the PS2_PET (N) and PS2_PET (S) systems.

\begin{tabular}{ccc}
\hline \multirow{2}{*}{ Packaging Component } & PS2_PET (N) & PS2_PET (S) \\
\cline { 2 - 3 } & Weight (g) & Weight (g) \\
\hline PET bottle (1st Packaging) & 22.8 & 25.7 \\
HDPE Cap (1st Packaging) & 1 & 1.5 \\
PE Label (1st Packaging) & 0.37 & 0.37 \\
Glue (1st Packaging) & 0.025 & 0.025 \\
PE Film (2nd Packaging) & 2.08 & 2.08 \\
Paper handle (2nd Packaging) & 0.26 & 0.26 \\
PE stretch film (3rd Packaging) & 0.59 & 0.59 \\
Cardboard sheet (3rd Packaging) & 2.71 & 2.71 \\
Wood Pallet * (3rd Packaging) & 27.78 & 27.78 \\
\hline
\end{tabular}

* Component not considered in the production phase because of the high reuse number.

Table 3 contains the primary inventory data for the washing phase of the reusable glass bottles that occurs in the bottling plant. An electricity consumption of 3.4 Wh per bottle was considered for the other plant operations (bottling, assembly and palletization) required by the PS1_GLASS system after the washing. For the PS2_PET systems, the 
electric energy required by all the bottling plant operations was about $14 \mathrm{Wh}$ per bottle (also including the blow moulding of the PET preforms). The amount of electricity needed by the company for all the industrial processes was taken from the national grid. Therefore, the Italian energy mix was considered in the analysis. For the reusable glass bottles, six reuses were considered. This value was provided by the bottling company based on the annual number of bottles that do not pass the control phase and are consequently replaced by new bottles (about 14\%). Therefore, the reusable glass bottles were used 7 times ( 6 reuse plus the first use).

Table 3. Inventory data about the washing phase of reusable glass bottles. The values refer to the functional unit of the study.

\begin{tabular}{ccc}
\hline Item & Unit & Value \\
\hline Input & & \\
Electricity & Wh & 7.4 \\
Water & $\mathrm{L}$ & 0.25 \\
Detergent (caustic soda 50\% solution) & $\mathrm{mL}$ & 8.12 \\
Output & & 0.25 \\
Wastewater & $\mathrm{L}$ & 0.12 \\
\hline
\end{tabular}

The distribution values in kgkm used for the modelling of this phase are reported in Table 4. Regarding to the return of the empty reusable glass bottles to the bottling company, the same distances of distribution (for both the distribution steps) were considered but without the weights of water and other components of the primary packaging.

Table 4. Main primary data of the distribution phase. The data are normalized in function of the FU of the study.

\begin{tabular}{cccc}
\hline \multirow{2}{*}{ Packaging System } & 1st Distribution & 2nd Distribution & Empty bottle return \\
\cline { 2 - 4 } & $\mathbf{k g k m}$ & $\mathbf{k g k m}$ & $\mathbf{k g k m}$ \\
\hline PS1_GLASS (N) & 361.3 & 50.1 & 144.1 \\
PS2_PET (N) & 228.9 & 31.7 & - \\
PS1_GLASS (S) & 255.0 & 50.1 & 101.7 \\
PS2_PET (S) & 162.1 & 31.7 & - \\
\hline
\end{tabular}

The modelling of the vehicles used for the distribution was performed through Ecoinvent v.3 database processes considering freight lorries Euro 5 of maximum size ( $>32$ metric tons) for the 1st distribution (from the bottling plant to the distribution centres) and freight lorries Euro 5 of size between 3.5 and 7.5 metric tons for the 2nd distribution (from the distribution centres to the retailers). The same modelling was performed for the return of the empty bottles to the plant. Information about size and category of the vehicles was provided by the company.

The end-of-life phase of the packaging systems was modelled, for each packaging material, with disposal scenarios composed of landfilling, incineration and recycling, as shown in Table 5. The percentage contributions of the three treatment processes were provided by the National Packaging Consortium for each type of material and refer to the Italian disposal scenario of packaging in 2019. 
Table 5. Inventory data about the percentage composition of the disposal scenarios for each packaging material.

\begin{tabular}{|c|c|c|c|c|}
\hline Packaging Material & Landfilling & Incineration & Recycling & Source \\
\hline Aluminium & $23.8 \%$ & $6.2 \%$ & $70.0 \%$ & $\begin{array}{l}\text { CiAl (National aluminium } \\
\text { Packaging Consortium) [24] }\end{array}$ \\
\hline Glass & $22.7 \%$ & $0 \%$ & $77.3 \%$ & $\begin{array}{c}\text { CoreVe (National glass Packaging } \\
\text { Consortium) [25] }\end{array}$ \\
\hline Paper-Cardboard & $11.6 \%$ & $7.6 \%$ & $80.8 \%$ & $\begin{array}{c}\text { Comieco (National paper-cardb. } \\
\text { Packaging Consortium) [26] }\end{array}$ \\
\hline PE-HDPE & $8.0 \%$ & $48.6 \%$ & $43.4 \%$ & $\begin{array}{c}\text { CorePla (National plastic } \\
\text { Packaging Consortium) [27] }\end{array}$ \\
\hline PET & $8.0 \%$ & $48.6 \%$ & $43.4 \%$ & $\begin{array}{l}\text { CorePla (National plastic } \\
\text { Packaging Consortium) [27] }\end{array}$ \\
\hline
\end{tabular}

The treatment processes of landfilling, incineration and recycling were modelled, for each material, following the same procedures and assumptions of Ferrara and De Feo (2020) [23]. The recycling processes were modelled taking into consideration the avoided virgin material, replaced by the secondary raw material produced by the recycling and, in this regard, a specific substitution ratio for each packaging material was considered as reported in Ferrara and De Feo (2020) [23].

\subsection{Life Cycle Impact Assessment}

The environmental impacts of the packaging systems were estimated with the use of the ReCiPe 2016 evaluation method adopting the hierarchist perspective $(\mathrm{H})$. This impacts calculation method is an updated and extended version of ReCiPe 2008 [28] that allows for the consideration of two approaches: the midpoint (problem oriented) level and the endpoint (damage oriented) level [23]. The midpoint approach consists of 18 impact categories: Global Warming Potential (GWP); Stratospheric Ozone Depletion (SOD); Ionizing Radiation (IR); Ozone Formation, Human Health (OF-HH); Fine Particulate Matter Formation (FPMF); Ozone Formation Terrestrial Ecosystems (OF-TE); Terrestrial Acidification (TA); Freshwater Eutrophication (FE); Marine Eutrophication (ME); Terrestrial Ecotoxicity (TEcotox); Freshwater Ecotoxicity (FEcotox); Marine Ecotoxicity (MEcotox); Human Carcinogenic Toxicity (HCTox); Human non-Carcinogenic Toxicity (HnCTox); Land Use (LU); Mineral Resource Scarcity (MRS); Fossil Resource Scarcity (FRS); Water Consumption (WC) [28]. A detailed description of all categories with the explanation of the indicators and the characterization factors for each category is reported in the paper of Huijbregts et al. (2017) [28].

In the endpoint approach, there are 22 categories that are grouped into three macroareas of protection: Human health (expressed in terms of disability adjusted life years, DALYs), Ecosystems (expressed in terms of species $\times$ year), and Resources (expressed in terms of USD 2013) [28].

The impact evaluation was carried out using both levels of the method and the results are presented with all the midpoint and endpoint categories. However, a part of the analysis was focused on the most representative midpoint categories, defined following the same approach of Cleary (2013). Such categories were those that provided the higher contribution to the endpoint level of the method:

- Global warming potential (GWP), that quantifies the integrated infrared radiative forcing increase of a greenhouse gas (GHG) and is expressed in $\mathrm{kg} \mathrm{CO}_{2}$-eq. [28].

- $\quad$ Fine particulate matter formation that considers the air pollution that causes primary and secondary aerosols in the atmosphere. It is expressed in $\mathrm{kg}$ PM2.5-eq.

- Terrestrial acidification, that estimates the atmospheric deposition of inorganic substances, such as sulphates, nitrates and phosphates, cause a change in acidity in the soil and is expressed in $\mathrm{n} \mathrm{kg} \mathrm{SO}_{2}$-eq. 
- Fossil resources scarcity, that considers the Fossil Fuel Potential, defined as the ratio between the higher heating value of a fossil resource and the energy content of crude oil. It is expressed in kg oil-eq. [28]

\section{Results and Discussion}

Figures 2 and 3 show the results of the comparison between the environmental performances of the two packaging systems for the natural mineral water, namely PS1_GLASS (N) and PS2_PET (N) (Figure 2) and for the sparkling mineral water, namely PS1_GLASS (S) and PS2_PET (S) (Figure 3), evaluated with the midpoint impact categories of ReCiPe 2016 (H). The values are reported in percentage terms, in function of the system with the highest impact value for each category.

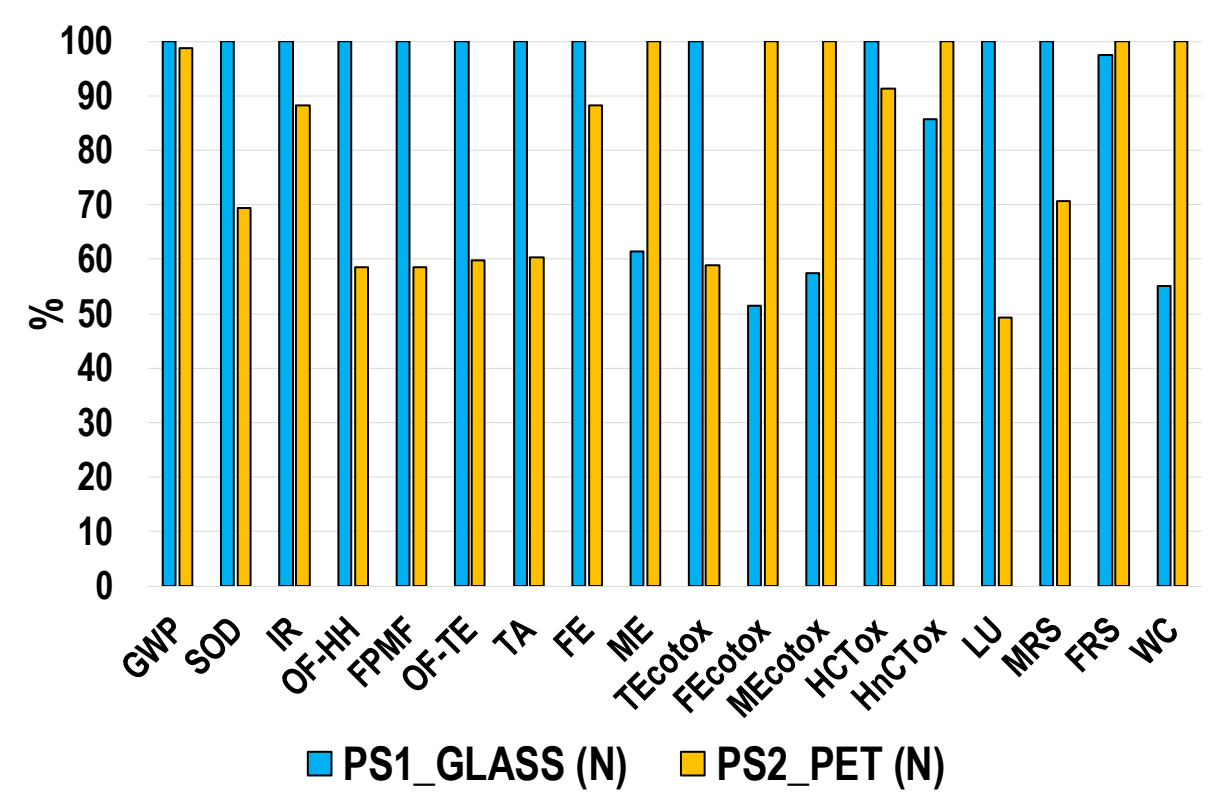

Figure 2. Comparison between the life cycle impacts of the considered packaging systems (PS1_GLASS and PS2_PET) for the natural drinking (N) water.

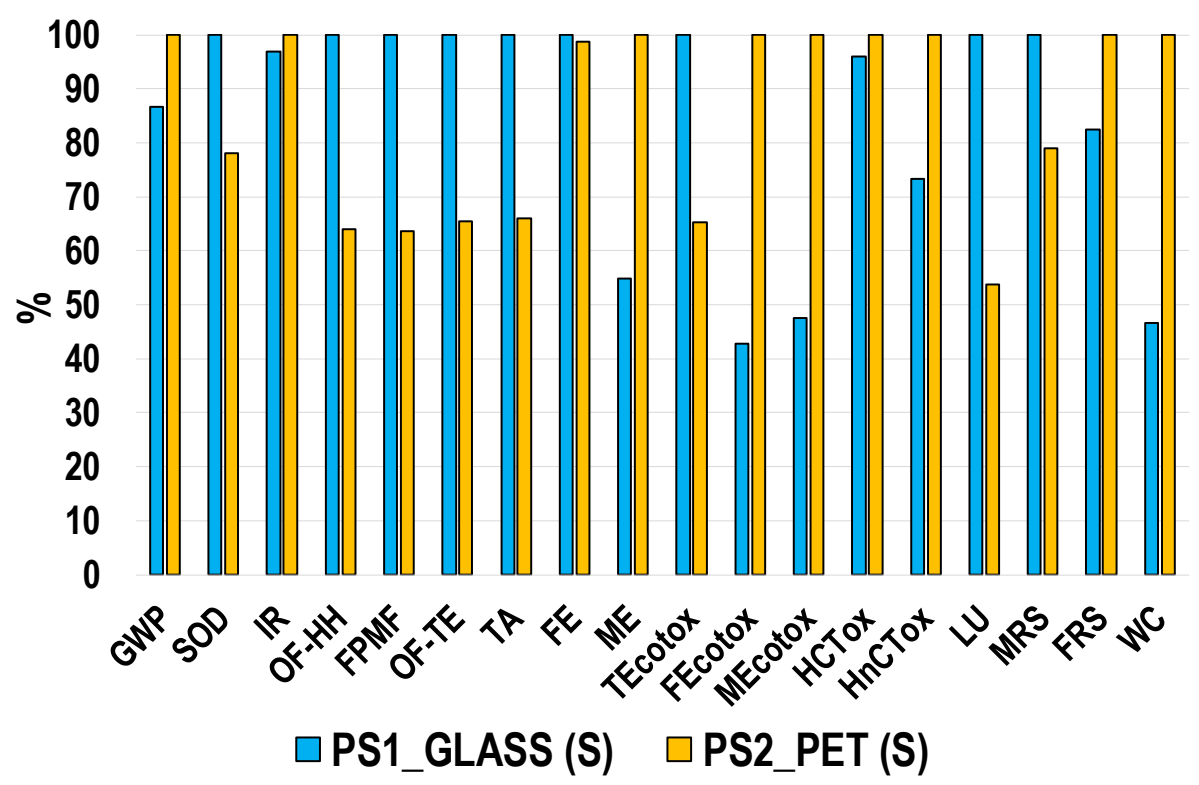

Figure 3. Comparison between the life cycle impacts of the considered packaging systems (PS1_GLASS and PS2_PET) for the sparkling drinking (S) water. 
The results highlighted that the PET bottle was the most environmentally sound alternative for the packaging of natural water with the greatest number of impacting categories, while for the sparkling water the environmental performances of the two packaging systems were similar and the best alternative changed according to the impact category considered. Therefore, in this case, it is not possible to uniquely identify the most sustainable solution.

These results occurred because the weight of the PET bottle and the plastic cap for the sparkling water is higher than those for the natural water (see Table 2) together with the high temperature occurring during the glass production process (i.e., about $1500^{\circ} \mathrm{C}$ ) and this caused greater impacts for the PS2_PET system. Furthermore, the distribution distance of the sparkling water is lower (see Table 4) and this aspect mainly benefits the glass packaging system due to the high weight to be transported [16].

The results obtained with the endpoint level of the ReCiPe 2016 method highlighted that the PS1_GLASS system was the most impactful packaging solution for both natural and sparkling water except in terms of resource consumption (Table 6).

Table 6. Potential environmental impacts of the considered packaging systems for natural $(\mathrm{N})$ and sparkling $(\mathrm{S})$ drinking water estimated with the endpoint categories of ReCiPe 2016.

\begin{tabular}{cccccc}
\hline Endpoint Category & Unit & PS1_GLASS (N) & PS2_PET (N) & PS1_GLASS (S) & PS2_PET (S) \\
\hline Human health & DALY & $4.19 \times 10^{-7}$ & $3.42 \times 10^{-7}$ & $3.75 \times 10^{-7}$ & $3.46 \times 10^{-7}$ \\
Ecosystems & species $\times$ yr & $9.18 \times 10^{-10}$ & $7.72 \times 10^{-10}$ & $8.11 \times 10^{-10}$ & $7.81 \times 10^{-10}$ \\
Resources & USD2013 & $2.37 \times 10^{-2}$ & $2.38 \times 10^{-2}$ & $2.00 \times 10^{-2}$ & $2.39 \times 10^{-2}$ \\
\hline
\end{tabular}

Similar results were discussed in other literature studies. Garfi et al. (2016) [15] highlighted that, from an environmental point of view, PET bottle was the preferable packaging alternative for mineral water. In the same way, Stefanini et al. (2020) [16] pointed out that for milk packaging, the reusable glass bottle had higher impacts compared to PET bottles. In both studies the authors considered eight uses for glass bottles (seven reuses plus first use).

Different results can be obtained considering a higher number of reuses for the glass bottles. Almeida et al. (2017) [19] compared, in environmental terms, different packaging for soft drinks and showed that the reusable glass bottles (reused 40 times) were the best environmental solution. Błazejewski et al. (2021) [17] focused on the milk supply chain comparing the environmental performances of the single use HDPE bottle and the reusable glass bottle assuming 283 reuses and pointed out that the latter packaging alternative could allow one to obtain considerable environmental saving for many impact categories. In the environmental comparison between PET bottles and reusable glass bottles for wine packaging, Ferrara et al. (2020) [23] highlighted that the latter had lower life cycle impacts considering 15 reuses.

More in general, Amienyo et al. (2014) [29] pointed out that the best environmental alternative for beverage between PET bottles and reusable glass bottles can vary depending on of the number of reuses for glass bottles.

The importance of the reuses number of glass bottles as a discriminating factor of the analysis also emerged from the results shown in Figure 4 regarding the contributions to the total impacts of the systems provided by each life cycle stage considered. Such steps are the following: Packaging production (i.e., the production of all components of the systems); Bottling plant operations (namely all activities that occur in the bottling company); Distribution (transportation of bottled water from the bottling company to the distribution centres and then to the retailers); End of life (disposal scenarios for each packaging material of the systems). 


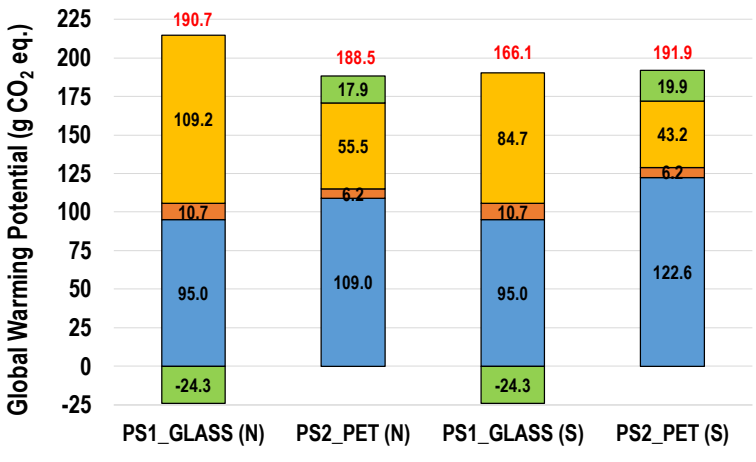

$\square$ Packaging production $\square$ Bott. Plant operations $\square$ Distribution $\square$ End of Life

(a)

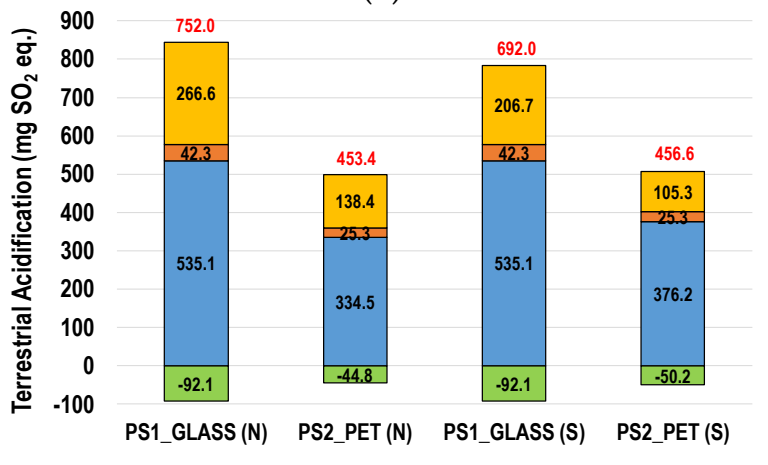

$\square$ Packaging production $\square$ Bott. Plant operations $\square$ Distribution $\square$ End of Life

(c)

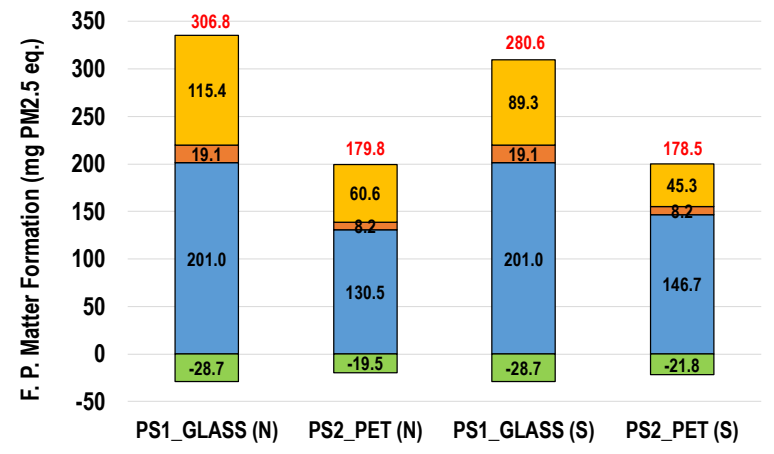

$\square$ Packaging production $\square$ Bott. Plant operations $\square$ Distribution $\square$ End of Life

(b)

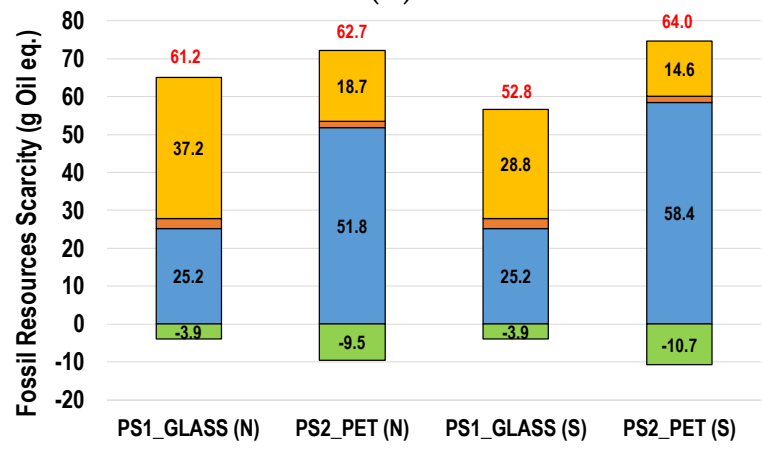

$\square$ Packaging production $\square$ Bott. Plant operations $\square$ Distribution $\square$ End of Life

(d)

Figure 4. Environmental impacts of the life cycle stages of the packaging systems for natural and sparkling water calculated with the most significant midpoint categories for this study: (a) Global warming; (b) Fine particulate matter formation (c) Terrestrial acidification (d) Fossil resources scarcity.

Looking at the PS1_GLASS system, it is worth noting that the highest contribution to the impacts of the packaging production phase was mainly due to the production of the glass amount necessary for the new glass bottles replacing the reusable bottles after seven uses. This amount of glass, normalized in function of the FU of the study was very low (about $64 \mathrm{~g}$ ). However, it was responsible for significant environmental burdens because of its energy-intensive production process [29]. Obviously, the amount of glass to be produced can be decreased by increasing the number of reuses. Consequently, the packaging production phase could be responsible for significantly lower impacts. On the other hand, the environmental benefits (i.e., avoided impacts) due to the end-of-life phase of the PS1_GLASS system were mainly due to the recycling processes of aluminium and glass amounts.

Another key aspect of the PS1_GLASS system was the distribution phase that affected the results for all the impact categories providing a high contribution to the total impacts of the system. This contribution was greater than $50 \%$ in terms of global warming potential and fossil resources scarcity. This aspect emerged even in the study of Tua et al. (2020) [30], where the authors pointed out that the contribution of the distribution can reach $80 \%$ of the total impacts of the reusable glass bottles.

In the case of sparkling water (PS1_GLASS (S)), the contribution of this phase to the total impacts was less significant due to the lower distribution distance: this was the only difference between the life cycle impacts of PS1_GLASS (N) and PS1_GLASS (S). Instead, for all the packaging systems considered, the bottling plant operations provided a negligible contribution compared to those provided by the other phases: this occurred for all the impact categories considered.

Looking at the PS2_PET system, the results highlighted that the production phase of the packaging components was the most impactful for all the impact categories and its 
contribution to the total impacts of the system was between $60 \%$ and $90 \%$ depending on the impact category and the type of bottled water (natural or sparkling water).

In the case of sparkling water (PS1_PET (S)), the production phase provided a higher contribution because of the higher weight of PET bottles.

The high impacts of the production phase of the PS2_PET system was mainly due to the significant environmental burdens derived from the PET granulate production [15,31] especially because, in this case study, the PET bottle was produced with $100 \%$ virgin PET. Using an amount of recycled PET in the bottle production could improve the environmental performance of the system [12,32]. About the distribution phase, the results showed that the contribution of this life cycle step to the impacts of PS2_PET was lower than PS1_GLASS because the former is much lighter, and this means lower fuel consumption as well as lower emissions during the transport phase.

Finally, focusing on the end-of-life phase of the two packaging alternatives, it is worth noting that the glass system registered higher environmental benefits mainly due to the recycling processes of the packaging materials [20]. The end-of-life of the PET system was less advantageous in environmental terms because of two main factors: the lower recycling rate and the lower quality of the secondary raw material produced by the recycling process compared to the virgin material [4].

\section{Conclusions}

The potential life cycle impacts of reusable glass bottles and PET bottles were compared to identify the most sustainable packaging system for the natural and sparkling water bottled and commercialized by an Italian mineral water company.

The results of the analysis highlighted that the PET bottle packaging system was globally the most environmentally sound solution for natural water, while the environmental performances of the two packaging systems for sparkling water were similar and the best alternative can vary in function of the impact category. The differences in the results between natural and sparkling water were mainly due to the greater weight of PET bottles as well as the lower distribution distance occurring in the case of sparkling water. The number of reuses for glass bottles and the distribution distance were the two parameters that influenced the results of the study the most. As the number of reuses increases and the distribution distances decrease, the environmental performance of the reusable glass bottle improves significantly. In this sense, a more careful management of the reusable glass bottles would be appropriate to increase the number of reuses. Therefore, the reuse program could be improved by the company involving customers with communication campaigns on the environmental benefits of the glass reuse.

The bottle production phase was the most impactful life cycle step of the PET bottle packaging system for all the impact categories: this was mainly due to the production of $100 \%$ virgin PET granulate used for the bottles. The environmental performances of the PET system could be improved using an amount of recycled PET in the bottle production. In this regard, the bottling company could act by purchasing PET preforms containing a percentage of Recycled PET (R-PET) and accordingly by informing consumers about the environmental advantages obtainable using the R-PET bottles.

Finally, the study highlights that currently it is not possible to determine which of the two alternative systems is the most sustainable packaging solution since it depends on the variation of the key factors identified in the analysis. Therefore, the adoption of the life cycle perspective pointed out that it is wrong to assume a priori that a reused glass bottle is better than a PET bottle and specific LCA analysis should be conducted on a case-by-case basis. 
Author Contributions: Conceptualization, G.D.F. and C.F.; methodology, G.D.F. and C.F.; software, G.D.F. and C.F.; validation, G.D.F. and C.F.; formal analysis, G.D.F. and C.F.; investigation, G.D.F., V.P. and C.F.; resources, G.D.F., V.P. and C.F.; data curation, G.D.F., V.P. and C.F.; writing-original draft preparation, G.D.F. and C.F.; writing-review and editing, G.D.F. and C.F.; visualization, G.D.F. and C.F.; supervision, G.D.F. and C.F. All authors have read and agreed to the published version of the manuscript.

Funding: This research received no external funding.

Institutional Review Board Statement: Not applicable.

Informed Consent Statement: Not applicable.

Data Availability Statement: The data presented in this study are available on request from the corresponding author.

Conflicts of Interest: The authors declare no conflict of interest.

\section{References}

1. Schwarz, A.E.; Ligthart, T.N.; Boukris, E.; van Harmelen, T. Sources, Transport, and Accumulation of Different Types of Plastic Litter in Aquatic Environments: A Review Study. Mar. Pollut. Bull. 2019, 143, 92-100. [CrossRef]

2. Boesen, S.; Bey, N.; Niero, M. Environmental Sustainability of Liquid Food Packaging: Is There a Gap between Danish Consumers' Perception and Learnings from Life Cycle Assessment? J. Clean. Prod. 2019, 210, 1193-1206. [CrossRef]

3. De Feo, G.; Ferrara, C. A Procedure for Evaluating the Most Environmentally Sound Alternative between Two On-Site Small-Scale Wastewater Treatment Systems. J. Clean. Prod. 2017, 164, 124-136. [CrossRef]

4. Sazdovski, I.; Bala, A.; Fullana-i-Palmer, P. Linking LCA Literature with Circular Economy Value Creation: A Review on Beverage Packaging. Sci. Total Environ. 2021, 771, 145322. [CrossRef]

5. Kouloumpis, V.; Pell, R.S.; Correa-Cano, M.E.; Yan, X. Potential Trade-Offs between Eliminating Plastics and Mitigating Climate Change: An LCA Perspective on Polyethylene Terephthalate (PET) Bottles in Cornwall. Sci. Total Environ. 2020, 727, 138681. [CrossRef]

6. Leivas, R.; Laso, J.; Abejón, R.; Margallo, M.; Aldaco, R. Environmental Assessment of Food and Beverage under a NEXUS Water-Energy-Climate Approach: Application to the Spirit Drinks. Sci. Total Environ. 2020, 720, 137576. [CrossRef] [PubMed]

7. Otto, S.; Strenger, M.; Maier-Nöth, A.; Schmid, M. Food Packaging and Sustainability-Consumer Perception vs. Correlated Scientific Facts: A Review. J. Clean. Prod. 2021, 298, 126733. [CrossRef]

8. Pasqualino, J.; Meneses, M.; Castells, F. The Carbon Footprint and Energy Consumption of Beverage Packaging Selection and Disposal. J. Food Eng. 2011, 103, 357-365. [CrossRef]

9. Saleh, Y. Comparative Life Cycle Assessment of Beverages Packages in Palestine. J. Clean. Prod. 2016, 131, 28-42. [CrossRef]

10. Gardas, B.B.; Raut, R.D.; Narkhede, B. Identifying Critical Success Factors to Facilitate Reusable Plastic Packaging towards Sustainable Supply Chain Management. J. Environ. Manag. 2019, 236, 81-92. [CrossRef] [PubMed]

11. Tamburini, E.; Costa, S.; Summa, D.; Battistella, L.; Fano, E.A.; Castaldelli, G. Plastic (PET) vs Bioplastic (PLA) or Refillable Aluminium Bottles-What Is the Most Sustainable Choice for Drinking Water? A Life-Cycle (LCA) Analysis. Environ. Res. 2021, 196, 110974. [CrossRef] [PubMed]

12. Horowitz, N.; Frago, J.; Mu, D. Life Cycle Assessment of Bottled Water: A Case Study of Green2O Products. Waste Manag. 2018, 76, 734-743. [CrossRef]

13. Camaratta, R.; Volkmer, T.M.; Osorio, A.G. Embodied Energy in Beverage Packaging. J. Environ. Manag. 2020, $260,110172$. [CrossRef] [PubMed]

14. Coelho, P.M.; Corona, B.; ten Klooster, R.; Worrell, E. Sustainability of Reusable Packaging-Current Situation and Trends. Resour. Conserv. Recycl. X 2020, 6, 100037. [CrossRef]

15. Garfí, M.; Cadena, E.; Sanchez-Ramos, D.; Ferrer, I. Life Cycle Assessment of Drinking Water: Comparing Conventional Water Treatment, Reverse Osmosis and Mineral Water in Glass and Plastic Bottles. J. Clean. Prod. 2016, 137, 997-1003. [CrossRef]

16. Stefanini, R.; Borghesi, G.; Ronzano, A.; Vignali, G. Plastic or Glass: A New Environmental Assessment with a Marine Litter Indicator for the Comparison of Pasteurized Milk Bottles. Int. J. Life Cycle Assess. 2021, 26, 767-784. [CrossRef]

17. Błażejewski, T.; Walker, S.R.; Muazu, R.I.; Rothman, R.H. Reimagining the Milk Supply Chain: Reusable Vessels for Bulk Delivery. Sustain. Prod. Consum. 2021, 27, 1030-1046. [CrossRef]

18. Cleary, J. Life Cycle Assessments of Wine and Spirit Packaging at the Product and the Municipal Scale: A Toronto, Canada Case Study. J. Clean. Prod. 2013, 44, 143-151. [CrossRef]

19. Almeida, C.M.V.B.; Rodrigues, A.J.M.; Agostinho, F.; Giannetti, B.F. Material Selection for Environmental Responsibility: The Case of Soft Drinks Packaging in Brazil. J. Clean. Prod. 2017, 142, 173-179. [CrossRef]

20. Simon, B.; Amor, M.B.; Földényi, R. Life Cycle Impact Assessment of Beverage Packaging Systems: Focus on the Collection of Post-Consumer Bottles. J. Clean. Prod. 2016, 112, 238-248. [CrossRef] 
21. International Organization for Standardization (ISO 14040). Environmental Management_Life Cycle Assessment-Principles and Framework: International Standard 14040; International Organization for Standardization: Geneva, Switzerland, 2006.

22. International Organization for Standardization (ISO 14044). Environmental Management_Life Cycle Assessment-Requirements and Guidelines; International Organization for Standardization: Geneva, Switzerland, 2006.

23. Ferrara, C.; De Feo, G. Comparative Life Cycle Assessment of Alternative Systems for Wine Packaging in Italy. J. Clean. Prod. 2020, 259, 120888. [CrossRef]

24. CiAl. Risultati Raccolta e Riciclo Alluminio 2019 (Results of Collection and Recycling of Aluminium 2019). Available online: http:/ / www.cial.it/risultati-riciclo-alluminio/ (accessed on 3 May 2021).

25. CoReVe. I Dati Della Raccolta del Vetro nel 2019 (Data of Glass Collection in 2019). Available online: https:/ / coreve.it/wpcontent/uploads/2020/10/PSP_2019_2020.pdf (accessed on 14 July 2021).

26. Comieco. Raccolta, Riciclo e Recupero Di Carta e Cartone 2019-25 Rapporto (Collection, Recycling and Recovery of Paper and Cardboard 2019 e 25th Report). Available online: https:/ / www.comieco.org/downloads/13484/8081/COMIECO_25Rapporto2020_21x21cm_10_web.pdf (accessed on 3 May 2021).

27. Corepla, 2019. Rapporto Di Sostenibilita 2019 (Sustainability Report 2019). Available online: https://www.corepla.it/documenti/ 060bbd18-7fbf-4b76-b9b8-d28f4a973607/RELAZIONE+SULLA+GESTIONE+2019.pdf (accessed on 3 May 2021).

28. Huijbregts, M.A.J.; Steinmann, Z.J.N.; Elshout, P.M.F.; Stam, G.; Verones, F.; Vieira, M.; Zijp, M.; Hollander, A.; van Zelm, R. ReCiPe2016: A Harmonised Life Cycle Impact Assessment Method at Midpoint and Endpoint Level. Int. J. Life Cycle Assess. 2017, 22, 138-147. [CrossRef]

29. Amienyo, D.; Camilleri, C.; Azapagic, A. Environmental Impacts of Consumption of Australian Red Wine in the UK. J. Clean. Prod. 2014, 72, 110-119. [CrossRef]

30. Tua, C.; Grosso, M.; Rigamonti, L. Reusing Glass Bottles in Italy: A Life Cycle Assessment Evaluation. Procedia CIRP 2020 90, 192-197. [CrossRef]

31. Kang, D.; Auras, R.; Singh, J. Life Cycle Assessment of Non-Alcoholic Single-Serve Polyethylene Terephthalate Beverage Bottles in the State of California. Resour. Conserv. Recycl. 2017, 116, 45-52. [CrossRef]

32. Fantin, V.; Scalbi, S.; Ottaviano, G.; Masoni, P. A Method for Improving Reliability and Relevance of LCA Reviews: The Case of Life-Cycle Greenhouse Gas Emissions of Tap and Bottled Water. Sci. Total Environ. 2014, 476-477, 228-241. [CrossRef] [PubMed] 